\title{
Diagnostic value of detailed metabolic pathway investigations in two cases of phaeochromocytoma with minimal increase in total catecholamine output
}

\author{
J. J. BROWN, C. R. J. RUTHVEN, AND M. SANDLER \\ From the Medical Unit, St. Mary's Hospital, London, and the Bernhard Baron Memorial \\ Research Laboratories and the Institute of Obstetrics and Gynaecology, \\ Queen Charlotte's Maternity Hospital, London
}

SYNOPSIS Two patients with phaeochromocytoma having atypical biochemical features are described. Total catecholamine excretion was normal in one and only slightly raised in the other; both had a diagnostic rise in output of metadrenaline and 4-hydroxy-3-methoxymandelic acid whilst 4-hydroxy-3-methoxyphenylglycol excretion was increased in one of them. During hypertensive attacks adrenaline excretion became greater than that of noradrenaline. The diagnostic usefulness of separate adrenaline and noradrenaline estimations in addition to catecholamine metabolite assay is discussed. A lack of relationship between tumour catecholamine content and urinary catecholamine output is emphasized.

The measurements of free catecholamines (Engel and Euler, 1950; Goldenberg, 1951; Lund, 1952; Hamilton, Litchfield, Peart, and Sowry, 1953; Goldenberg, Serlin, Edwards, and Rapport, 1954; Euler and Floding, 1956; Bollman, Flock, Roth, and Kvale, 1960) or one or more of their major urinary metabolites (Gitlow, Mendlowitz, Kruk, and Khassis, 1961 ; Crout, Pisano, and Sjoerdsma, 1961; Robinson, 1963; Kelleher, Walters, Robinson, and Smith, 1964) are now firmly established as valuable procedures in the diagnosis of phaeochromocytoma. Although usually reliable, none of these laboratory tests is infallible. Litchfield and Peart (1956) described a patient with a phaeochromocytoma and a normal catecholamine excretion even during typical attacks. The patient of Kraupp, Stormann, Bernheimer, and Obernaus (1959) was similar except during attacks, when a raised catecholamine excretion was observed, although a constant increase in 4-hydroxy-3-methoxymandelic acid (V.M.A.) output was noted at all times. Crout et al. (1961) reported the converse, an increase in catecholamine excretion with a normal output of metabolites; others (Kelleher and Walters, 1961; Robinson, 1963; Kelleher et al., 1964) have subsequently indicated Received for publication 28 April 1966. that the catecholamines and their various metabolites need not be uniformly elevated in urine from affected patients but that the metadrenalines often show the greatest proportional rise. No patient with phaeochromocytoma has so far been recorded in whom all tests have been normal.

The value of a further diagnostic aid, the differential estimation of adrenaline and noradrenaline, was stressed by Hunter, Marshall, and Oram (1963). This procedure is particularly useful when the excretion of total catecholamines is normal or only marginally raised. The two cases presented here fall into such a category. They illustrate the value of the separate determination of adrenaline and noradrenaline and the estimation of a wide range of metabolites when it is not possible to make a diagnosis by total catecholamine assay alone.

\section{METHODS}

URINE Twenty-four-hour urine specimens were collected over $10 \mathrm{ml} .10 \mathrm{~N}-\mathrm{HCl}$.

DETERMINATION OF TOTAL URINARY CATECHOLAMINES Catecholamines were extracted from $200 \mathrm{ml}$. aliquots of urine using the method of Euler and Hellner (1951). Total catecholamines were assayed using the blood pressure response of the anaesthetised rat (Crawford and 
Outschoorn, 1951; Hamilton et al., 1953; Peart, 1955) and calculated by comparison with noradrenaline (Levophed, l-noradrenaline bitartrate, Bayer Products Ltd.,) as a standard. The mean recovery of added noradrenaline was $75-85 \%$ and the normal adult range was equivalent to $15-100 \mu \mathrm{g}$. noradrenaline per 24 hours.

DIFFERENTIAL DETERMINATION OF ADRENALINE AND NORADRENALINE IN URINE After determining the relative pressor potencies of adrenaline and noradrenaline, the assay rat was given $1 \mathrm{mg}$. dihydroergotamine (Sandoz) intravenously (Hamilton et al., 1953); this abolished the response to noradrenaline and permitted an estimation of 'adrenaline' by assaying the depressor responses then obtained with the urinary extract against standard adrenaline (1-adrenaline tartrate, May and Baker, Ltd.) The noradrenaline content was then calculated by difference, allowing for the differing pressor potencies of adrenaline and noradrenaline. The range in five normal subjects and seven patients with essential hypertension was: adrenaline 3-50 $\mu \mathrm{g}$. $/ 24 \mathrm{hr}$.; noradrenaline 10-70 $\mu \mathrm{g} . / 24$ hr. (J. J. Brown, unpublished data).

DETERMINATION OF NORADRENALINE AND ADRENALINE IN TUMOUR TISSUE An extract prepared by grinding a small piece of tumour tissue with a little silver sand and $0 \cdot 1 \mathrm{~N}-\mathrm{HCl}(10 \mathrm{ml} . / \mathrm{g}$. wet weight $)$ was estimated by the method for urinary catecholamines.

DETERMINATION OF URINARY CATECHOLAMINE METABOLITES The concentration of V.M.A. was estimated by the method of Sandler and Ruthven (1959 a, b) (normal range 4.0$8.2 \mathrm{mg} . / 24 \mathrm{hr}$.) for case 1 and by that of Pisano, Crout, and Abraham (1962) (normal range 1·8-7.1 mg./24 hr.) for case 2. Total metadrenalines (normal range 0.3$0.8 \mathrm{mg} . / 24 \mathrm{hr}$ ) and 4-hydroxy-3-methoxyphenylglycol (H.M.P.G.) (normal range 1.9-5.2 mg./24 hr.) were estimated by the procedure of Ruthven and Sandler (1965).

\section{CLINICAL OBSERVATIONS AND RESULTS}

CASE 1 This patient was a 47-year-old Welsh slate quarry worker admitted to the Brompton Hospital, London, in 1959 under the care of the late Dr. Paul Wood who first suggested the diagnosis of phaeochromocytoma. For two years, the patient had complained of excessive breathlessness on exertion and mitral stenosis was diagnosed before he was transferred to St. Mary's Hospital, Paddington, London, under the care of Professor W. S. Peart. Since 1952 he had experienced attacks of severe nausea, throbbing pain in the left temporal region, pallor, tremor of the limbs, a sensation of great anxiety, and a 'thumping' sensation in the praecordium. Attacks occurred during the day or night without warning, varied in duration from 10 to 60 minutes, originally occurred infrequently (one a month) but latterly increased to two per week.

Examination Apart from the signs of mitral stenosis there were no abnormal findings between attacks. The blood pressure was $140 / 85 \mathrm{~mm}$. $\mathrm{Hg}$ and the pulse regular at 70 per minute. Several spontaneous attacks were observed during which the patient became pale, developed a tremor, and sweated profusely. The pulse rate and blood pressure increased (maximum 250/150 mm. Hg). An E.C.G. during one attack revealed an irregular supraventricular tachycardia with a rate of 200 per minute.

Investigations The urine did not contain reducing substances or protein. Plasma electrolytes, blood urea, haemoglobin, white blood count, and chest radiography were normal.

In spite of symptoms associated with excess circulating pressor amines the daily catecholamine excretion was normal (Table). This finding led us to estimate noradrenaline and adrenaline in urine samples collected in two consecutive three-hour periods, during the first of which a spontaneous attack occurred. The total output of free amines was again not high (Table), but the marked preponderance of adrenaline was taken to support the

TABLE

CATECHOLAMINE EXCRETION IN CASES 1 AND 2

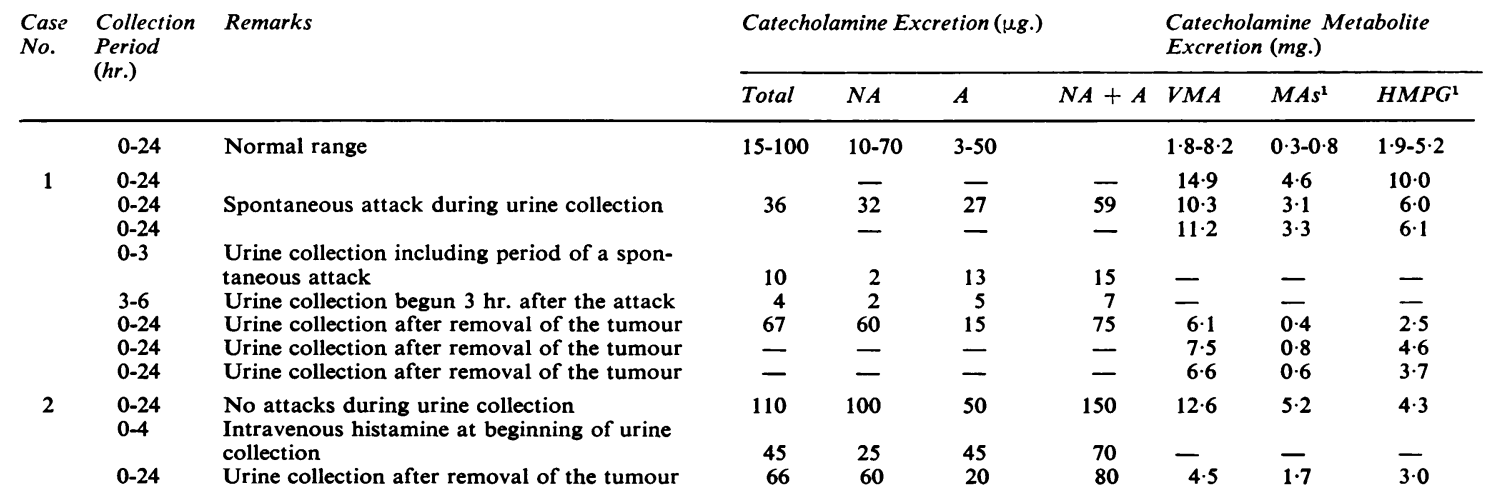

${ }^{1}$ Free plus conjugated metabolite

Abbreviations used: noradrenaline $=$ NA; adrenaline $=$ A; 4-hydroxy-3-methoxymandelic acid $=$ VMA; metadrenalines $=$ MAs; 4-hydroxy3-methoxyphenylglycol = HMPG. 
diagnosis of an adrenal phaeochromocytoma. Intravenous injection of a solution containing $100 \mu \mathrm{g}$. adrenaline and $20 \mu \mathrm{g}$. noradrenaline produced symptoms similar to those of a spontaneous attack; the blood pressure increased to $200 / 120 \mathrm{~mm}$. $\mathrm{Hg}$ but the pulse rate did not alter. Presacral retroperitoneal pneumography was performed followed by tomography, and the late Dr. E. Rohan Williams reported 'an undoubted tumour 4-4.5 $\mathrm{cm}$. in diameter in immediate relationship to the upper pole of the right kidney. The left suprarenal area shows normal appearances'. The patient then received phenoxybenzamine $20 \mathrm{mg}$. t.d.s. for the five days before operation; during this time there were no spontaneous attacks.

In contrast to the amines themselves, the excretion of catecholamine metabolites was unequivocally increased. The output of V.M.A. and total H.M.P.G. output were about twice normal, whereas the total metadrenaline excretion was at least five times the normal mean (Table). The output of all fell to normal after the removal of the tumour (Table).

Operation This was performed on 20 June 1959 by Mr. Kenneth Owen. The right adrenal gland, containing a spherical tumour in its upper part, was removed without difficulty. There were no marked changes in blood pressure during the operation or afterwards. The tumour weighed $45 \mathrm{~g}$., measured $4.5 \times 3.5 \mathrm{~cm}$., and contained $1.25 \mathrm{mg}$. noradrenaline and $20 \mathrm{mg}$. adrenaline per gram wet weight.

CASE 2 This patient was a 48-year-old unmarried woman admitted to St. Mary's Hospital, London, in February 1962 under the care of Dr. J. W. Litchfield who made the clinical diagnosis of phaeochromocytoma. For two and a half years the patient had noticed attacks of tremor and weakness, particularly affecting the lower limbs, severe occipital headache and nausea without vomiting. During some attacks she had observed a slowing of the pulse rate to 60 per min. and blurring of near vision. Seven severe attacks each lasting approximately one hour had occurred, but in addition less pronounced symptoms of a similar nature developed two or three times a week. The patient's brother had a phaeochromocytoma removed from the right adrenal in 1949 (case 2 , Hamilton et al., 1953) and from the left adrenal in 1962 (Brown, Litchfield, and Wright, 1966).

Examination She was a rather thin, very alert woman whose blood pressure was $145 / 90 \mathrm{~mm} . \mathrm{Hg}$ and pulse rate regular at 70 per min. A $1 \mathrm{~cm}$., and probably cystic, swelling was present in the right upper lobe of the thyroid gland. Despite the familial history of phaeochromocytoma, this swelling was not considered to be a medullary cell carcinoma (c.f. Williams, 1965).

Spontaneous attacks did not occur while she was in hospital.

Investigations There was no reducing substance or protein in the urine, and the blood sugar, haemoglobin, plasma electrolytes, chest radiograph, and intravenous pyelograms were normal. Intravenous injection of histamine (10 $\mu \mathrm{g}$. as base) produced sensations similar to those occurring in the less severe spontaneous attacks. Blood pressure increased from $145 / 90$ to $170 / 115 \mathrm{~mm}$. $\mathrm{Hg}$ and the pulse rate fell from 90 to 55 per minute.
Two minutes after injecting $25 \mu \mathrm{g}$. of histamine intraveneously, the blood pressure reached $225 / 150 \mathrm{~mm}$. $\mathrm{Hg}$ and the pulse was irregular at a rate of 130 per minute. Phentolamine (5 mg.) was then injected intravenously; one minute later the blood pressure was $120 / 60 \mathrm{~mm}$. Hg and the pulse again regular at 90 per minute. Pre-sacral retroperitoneal pneumography followed by anteroposterior and lateral tomography revealed an almost spherical tumour measuring approximately $5 \times 4.5 \mathrm{~cm}$. lying anterior to the upper pole of the left kidney (Dr. E. Rohan Williams).

The total pressor activity (expressed in terms of noradrenaline) in urine collected during a 24-hr. period free from attacks barely exceeded the upper limit of normal $(100 \mu \mathrm{g}$.). However, when the amines were assayed separately, the total excretion was raised; futhermore the ratio of adrenaline to noradrenaline was high both in the 24-hour urine sample and in the urine collected across the histamine-provoked attack (Table).

Output of V.M.A. and metadrenaline was diagnostically raised, similarly to case 1 , although total H.M.P.G. excretion was within normal limits (Table).

Operation A phaeochromocytoma was removed from the left adrenal gland, to which it was attached by a thin ridge of tissue, by Mr. A. Dickson Wright on 9 March 1962. The tumour weighed $30 \mathrm{~g}$. and contained $50 \mu \mathrm{g}$. adrenaline and $20 \mu \mathrm{g}$. noradrenaline per gram wet weight. The operative and post-operative courses were uneventful and the symptoms have not recurred.

\section{DISCUSSION}

The two patients presented here did not have any marked increase in catecholamine excretion, in contrast to the usual finding in phaeochromocytoma. Of the few similar cases reported, that of Litchfield and Peart (1956), like case 1 , had a normal catecholamine output even during paroxysmal attacks. Metabolic degradation pathways for the catecholamines were largely unknown in 1956; had tests been available, it is possible that an increased metabolite output would have been detected in this patient. Similar cases with a normal or near normal excretion of catecholamines have since been shown to have a raised output of V.M.A. (Gitlow, Mendlowitz, Khassis, Cohen, and Sha, 1960; Jacobs, Sobel, and Henry, 1961) or metadrenalines (Gjessing and Hjermann, 1964). Crout et al. (1961) considered the level of urinary catecholamines to be the most reliable single diagnostic index of phaeochromocytoma, but there is a considerable body of evidence (Kelleher et al., 1964; Gjessing and Hjermann, 1964; Sandler and Ruthven, 1966), supported by the present findings, to suggest that output of total metadrenalines is at least as useful a guide as catecholamine excretion in the detection of phaeochromocytoma.

Although extra-adrenal phaeochromocytomas often are pure noradrenaline secretors, the more common adrenal tumours (Hermann and Mornex, 
1964) tend to secrete a mixture of amines. In these, the differential determination of adrenaline and noradrenaline is superior to the assay of total catecholamines alone as a diagnostic tool (Hunter et al., 1963). In the normal subject, the excretion of noradrenaline is usually considerably greater than that of adrenaline, although Hunter et al. (1963) observed noteworthy day-to-day fluctuations. The marked preponderance of adrenaline over noradrenaline excretion during attacks in cases 1 and 2 was sufficiently unusual to support the clinical diagnosis, despite the low total pressor amine excretion. This increase in adrenaline output is in agreement with the urinary pattern of catecholamine excretion arising from a tumour located within (case 1) the adrenal or adjacent (case 2) to it (Crout and Sjoerdsma, 1960).

Although the tumours in each of our patients were of approximately the same size, the concentration of adrenaline in that of case 1 was about 400 times greater than that of case 2 ; nevertheless, the daily urinary output of adrenaline in the former was less than in the latter. A similar lack of correlation was noted by Bollmann et al. (1960). The high tumour catecholamine level, particularly in case 1 , and the appreciable increase in output of metabolites in contrast to the low excretion of pressor amines, suggest that significant amounts of amine may have been metabolized in the tumour tissue itself. Both catechol 0-methyltransferase and monoamine oxidase, which are largely responsible for inactivation (Axelrod, 1963), have been identified in phaeochromocytoma tissue by Sjoerdsma, Leeper, Terry, and Udenfriend (1959).

In studies on the turnover and metabolism of catecholamines in patients with phaeochromocytoma, Crout and Sjoerdsma (1964) obtained evidence to suggest that small tumours (less than $50 \mathrm{~g}$.) have a rapid rate of turnover and tend to secrete a relatively pure infusion of amine into the host. On the other hand larger tumours, with a lower turnover, tend to put out a greater proportion of metabolites. These observations would seem to be at variance with the findings reported here. However, Crout and Sjoerdsma point out that the difference between tumour size and catecholamine excretion probably relates to type rather than size of tumour, since the slow secretor may escape detection more easily in the early stages of its growth. The two tumours in the present cases would presumably have grown larger had they been left in situ; it is reasonable to suppose that their catecholamine excretion would then have risen sufficiently to produce abnormal levels in the urine. Leather, Shaw, Cates, and Walker (1962) investigated a patient with a normal catecholamine output, who two years later, when the final diagnosis of phaeochromocytoma was made, was putting out increased amounts of catecholamine.

It is fortunate that cases such as those described here form a small minority of patients undergoing laboratory investigation for suspected phaeochromocytoma. In the typical case, a positive diagnosis will be reached whichever biochemical yardstick is employed. Nevertheless, the difficult case is always likely to arise and for this, Sandler (1964) has suggested the following approach:-

(1) Carry out V.M.A. assay (Pisano et al. 1962) on $24 \mathrm{hr}$. urine sample; (2) if the answer is less than $6 \mathrm{mg} . / 24 \mathrm{hr}$. no further action is necessary unless strong clinical suspicion remains; (3) if a value between 6 to $8.5 \mathrm{mg} . / 24 \mathrm{hr}$. is obtained, or if the clinicians press, carry out three further V.M.A. assays on 24-hr. urine samples; (4) if equivocal values are still obtained, carry out total metadrenaline assay (Pisano, 1960, or preferably, Ruthven and Sandler, 1965); (5) if no firm answer is arrived at (that is, if the total metradrenaline excretion lies between 0.8 and $1.5 \mathrm{mg} . / 24 \mathrm{hr}$.), carry out differential catecholamine assay.

We wish to thank Professor W. S. Peart and Dr. J. W. Litchfield for permission to refer to these patients and Mr. A. Dickson Wright and Mr. Kenneth Owen for the operative findings.

\section{REFERENCES}

Axelrod, J. (1963). In West-European Symposium on Clinical Chemistry. Vol 2: The Clinical Chemistry of Monoamines, edited by H. Varley, and A. H. Gowenlock, p. 7. Elsevier, Amsterdam.

Bollman, J. L., Flock, E. V., Roth, G. M., and Kvale, W. F. (1960). J. Lab. clin. Med., 56, 506.

Brown, J. J., Litchfield, J. W., and Wright, A. D. (1966). Postgrad. med. J., 42, 203.

Crawford, T. B. B., and Outschoorn, A. S. (1951). Brit. J. Pharmacol., $6,8$.

Crout, J. R., and Sjoerdsma, A. (1960). Circulation, 22, 516. (1964). J. clin. Invest., 43, 94.

_ Pisano, J. J., and Sjoerdsma, A. (1961). Amer. Heart J., 61, 375. Engel, A., and Euler, U. S. von (1950). Lancet, 2, 387.

Euler, U. S. von, and Hellner, S. (1951). Acta physiol. scand., 22, 161.

-, and Floding, I. (1956). Scand. J. clin. Lab. Invest., 8, 288.

- and Lishajko, F. (1959). Acta physiol. scand., 45, 122.

Gitlow, S. E., Mendlowitz, M., Khassis, S., Cohen, G., and Sha, J. (1960). J. clin. Invest., 39, 221.

- - Kruk, E., and Khassis, S. (1961). Circulat. Res., 9, 746.

Gjessing, L. R., and Hjermann, I. (1964). Lancet, 2, 1014.

Goldenberg, M. (1951). Amer. J. Med., 10, 627.

-, Serlin, I., Edwards, T., and Rapport, M. M. (1954). Ibid., $16,310$.

Hamilton, M., Litchfield, J. W., Peart, W. S., and Sowry, G. S. C. (1953). Brit. Heart J., 15, 241.

Hermann, H., and Mornex, R. (1964). Human Tumours Secreting Catecholamines. Pergamon, Oxford, London.

Hunter, R. B., Marshall, P. B., and Oram, F. J. (1963). Quart. J. Med., 32, 225.

Jacobs, S. L., Sobel, C., and Henry, R. J. (1961). J. clin. Endocr., $21,315$.

Kelleher, J., and Walters, G. (1961). Lancet, 2, 1312.

-, Walters, G., Robinson, R., and Smith, P. (1964). J. clin. Path., $17,399$.

Kraupp, O., Stormann, H., Bernheimer, H., and Obennaus, H. (1959). Klin. Wschr., 37, 76.

Leather, H. M., Shaw, D. B., Cates, J. E., and Walker, R. M. (1962). Brit. med. J., 1, 1373.

Litchfield, J. W., and Peart, W. S. (1956). Lancet, 2, 1283. 
Lund, A. (1952). Scand. J. clin. Lab. Invest., 4, 263.

Peart, W. S. (1955). Biochem. J., 59, 300.

Pisano, J. J. (1960). Clin. chim. Acta, 5, 406.

, Crout, J. R., and Abraham, D. (1962). Ibid., 7, 285.

Robinson, R. (1963). In West-European Symposium on Clinical Chemistry. Vol. 2: The Clinical Chemistry of Monoamines, edited by $H$. Varley and A. H. Gowenlock, p. 63. Elsevier, Amsterdam.

-, and Smith, P. (1962). Clin. chim. Acta, 7, 29.

Ruthven, C. R. J., and Sandler, M. (1965). Ibid., 12, 318.
Sandler, M. (1964). J. med. Lab. Technol., 21, 306.

-, and Ruthven, C. R. J. (1959a). Lancet, 2, 114.

- - (1959b). Ibid., 2, 1034.

- _ (1961). Biochem. J., 80, 78.

-, - (1966). In Recent Results in Cancer Research. II. Neuroblastomas, Biochemical Studies, edited by C. Bohoun, p. 55. Springer-Verlag, Berlin.

Sjoerdsma, A., Leeper, L. C., Terry, L. L., and Udenfriend, S. (1959). J. clin. Invest., 38, 31.

Williams, E. D. (1965). J. clin. Path., 18, 288. 